\title{
WIND TOWERS - DESIGN OF FRICTION CONNECTIONS FOR ASEMBLING SECTIONS OF TUBULAR STEEL TOWERS
}

\author{
MSc Nenad Fric* \\ University of Belgrade, Faculty of Civil Engineering, Belgrade, Serbia \\ MSc Boris Gligić \\ University of Belgrade, Faculty of Civil Engineering, Belgrade, Serbia \\ MSc Jelena Dobrić \\ University of Montenegro, Faculty of Civil Engineering, Podgorica, Montenegro \\ Dr Zlatko Marković \\ University of Belgrade, Faculty of Civil Engineering, Belgrade, Serbia
}

The towers represent about 15 to $20 \%$ of the total installation costs and optimized design may therefore lead to substantial savings with regard to costs and use of materials. Some of the most interesting design and manufacturing details are connections used to assemble sections of tubular steel towers supporting wind turbines. There is traditional flange ring connection and on the other side, as a new proposal, friction connection. In this paper theoretic basis of design of friction connection of wind towers is given.

Keywords: wind tower, friction connection, tension controlled bolts, friction surfaces

\section{GENERAL}

Currently, assembling sections of tubular steel towers with bolted ring flange connections is more often used than the friction connections. Bolted flange ring connection consists of steel rings which are welded at both tube ends and of high strength bolts which connect these rings. Friction connections constitute an innovative solution (in alternative to the flange connections) for assembling joints in tubular towers for wind turbines.

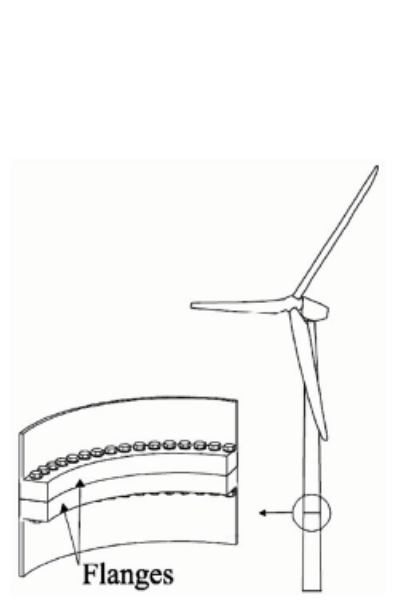

Figure 1. Bolted L-flange ring connection
Concerning the conception of the new configuration:

- it uses tension control bolts (TCB), tightened by rotation of the nut (inside of the tower),

- the bolts are preinstalled in normal holes on the upper segment of the tower,

- or easy assembly it is used long open slotted holes on the lower segment of the tower.

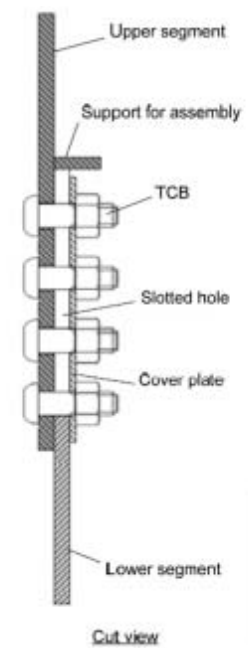

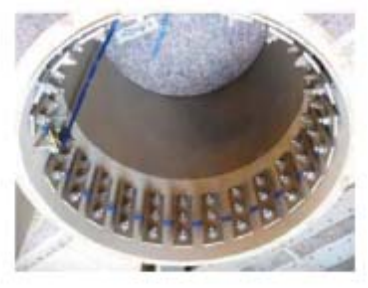

Inside view

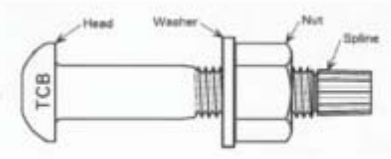

Figure 2. Main concept of the friction connection in tubular tower for wind 

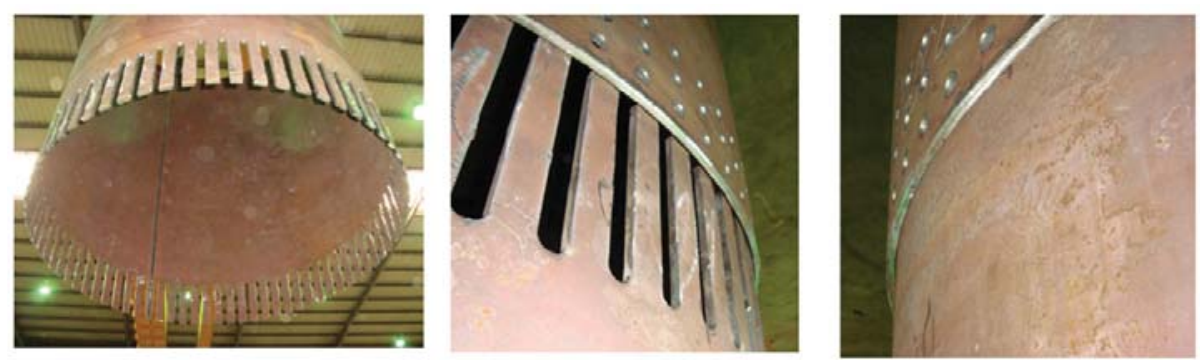

Figure 3. Main concept of the friction connection in tubular tower for wind turbines

Tension Control Bolts (TCBs) are a special type of high strength fasteners initially developed in Japan (Figure 4).

This type of fasteners was chosen because it was available on the market and for its simple installation. The producer claims that tightening procedure can be up to two times quicker and require four times less man hours than compared to normal bolts. It might also be advantageous to rely on electrical power rather than pneumatic or hydraulic power which are more difficult to provide during assembly of a wind tower.

The mechanical properties are equivalent to those of High Strength Bolts. Grade S10T may be considered as bolt grade 10.9.

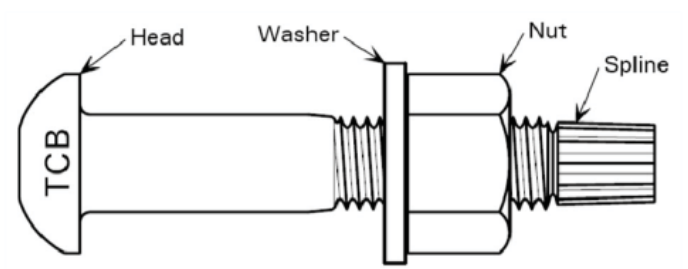

Figure 4. Tension control bolts, Grade S10T (prior to pretendioning) tensioning, thightening

Their tightening is carried out entirely at the nut end (See Figure 5) with a special electric wrench. The spline is held by the inner socket while the outer socket rotates and turns the nut (a). An increasing tightening torque develops between inner and outer socket. When the resistance of the calibrated break-neck is reached it shears off, allowing the inner socket to rotate (b).
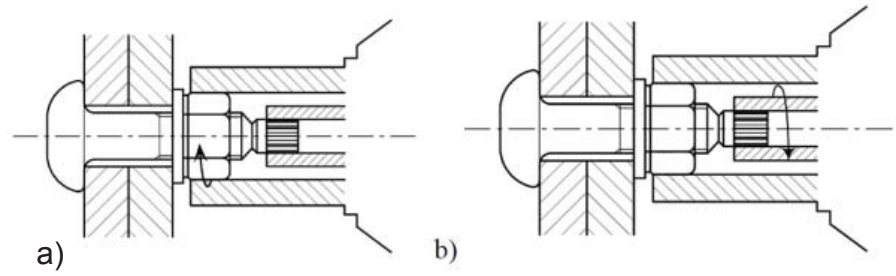

Figure 5. Tension control bolts - tightening procedure

\section{DESIGN OF FRICTION CONNECTIONS}

Friction connection is a connection where the resistance and the stiffness are achieved by the friction action between the joint plates.

The global behaviour depends mainly of two key parameters:

1. Preload force in the bolts (high strength bolts)

2. Slip factor $\mu$ between contact surfaces (surface roughness and surface treatment).

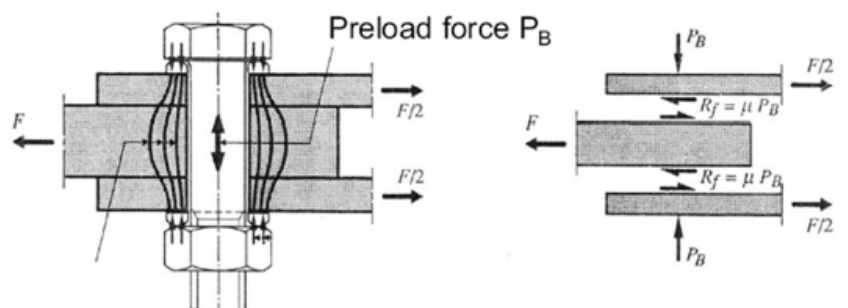

Figure 6. Load transfer

mechanism - friction connection

\section{DESIGN OF FRICTION CONNECTIONS ACCORDING TO EUROCODES}

In Europe, the analysis and design of friction connections are predicted in Eurocode 3: Design of Steel Structures, Part 1.8: Design of joints.

The execution specifications are covered by EN 1090: Execution of steel structures and aluminium structures, Part 2: Technical requirements for steel structures.

In friction connections of Category C (slip-resistant at ultimate limit states) the failure modes are:

1. Slip resistance - Fs, Rd (in general the governing mode):

$\mathrm{F}_{\mathrm{s}, \mathrm{Rd}}=\frac{\mathrm{k}_{\mathrm{s}} \cdot \mathbf{n} \cdot \boldsymbol{\mu}}{\gamma_{\mathrm{M} 3}} \cdot \mathrm{F}_{\mathrm{p}, \mathrm{C}}$

$F_{p, C}=0,7 \cdot f_{u b} A_{s}$ 
$\mu$ - slip factor (Table 18 of EN 1090-2),

$\mathrm{n}$ - number of contact surfaces,

ks - parameter ( $k s=1.0$ for normalized holes; $\mathrm{ks}=0.63$ for slotted long holes),

$\mathrm{Y}_{M 3}-$ partial safety factor taken as $\mathrm{YM}=1.25$

Table 1. Categories of bolted connections

\begin{tabular}{|c|c|c|}
\hline Category & Criteria & Remarks \\
\hline \multicolumn{3}{|c|}{ Shear connections } \\
\hline $\begin{array}{c}\text { A } \\
\text { bearing type }\end{array}$ & $\begin{array}{l}F v, E d \leq F v, R d \\
F v, E d \leq F b, R d\end{array}$ & $\begin{array}{l}\text { No preloading required. } \\
\text { Bolt classes from } 4.6 \text { to } 10.9 \text { may be used. }\end{array}$ \\
\hline $\begin{array}{c}\text { B } \\
\text { Slip-resistant at serviceability }\end{array}$ & $\begin{aligned} F v, E d, \text { ser } & \leq F s, R d, \text { ser } \\
F v, E d & \leq F v, R d \\
F v, E d & \leq F b, R d\end{aligned}$ & $\begin{array}{c}\text { Preloaded } 8.8 \text { or } 10.9 \text { bolts } \\
\text { should be used.For slip resistance } \\
\text { at serviceability see } 3.9 \text {. }\end{array}$ \\
\hline $\begin{array}{c}\text { C } \\
\text { Slip-resistant at ultimate }\end{array}$ & $\begin{aligned} F v, E d & \leq F s, R d \\
F v, E d & \leq F b, R d \\
F v, E d & \leq \text { Nnet,Rd }\end{aligned}$ & $\begin{array}{c}\text { Preloaded } 8.8 \text { or } 10.9 \text { bolts } \\
\text { should be used.For slip resistance } \\
\text { at ultimate see 3.9.Nnet, Rd see } 3.4 .1(1) \mathrm{c}) \text {. }\end{array}$ \\
\hline
\end{tabular}

2. Bearing of the bolts or the joined plates due to contact pressure - Fb,Rd:

$\mathrm{F}_{\mathrm{b}, \mathrm{Rd}}=\frac{\mathrm{k}_{1} \cdot \alpha_{\mathrm{b}} \cdot \mathrm{f}_{\mathrm{u}} \cdot \mathrm{d} \cdot \mathrm{t}}{\gamma_{\mathrm{M} 2}}$

3. Net resistance $-\mathrm{N}_{\text {net,Rd }}$ :

$$
\mathrm{N}_{\text {net,Rd }}=\frac{0.9 \cdot \mathrm{A}_{\text {net }} \cdot \mathrm{f}_{\mathrm{u}}}{\gamma_{\mathrm{M} 0}}
$$

\section{DESIGN OF FRICTION CONNECTIONS PROPOSED TO USE IN WIND TOWERS}

In the configuration of friction connection proposed to use in wind towers, there are some differences, when compared with normal friction connections. The ultimate resistance can be determined according to the following failure modes:

1. Ultimate slip design resistance $\mathrm{Zs,Rd}$ of one bolt row of the friction joint (segment model):

$$
\mathrm{Z}_{\mathrm{s}, \mathrm{Rd}}=\frac{\mathrm{n}_{\mathrm{s}} \cdot \mu \cdot \mathrm{k}_{\mathrm{s}} \cdot \mathrm{F}_{\mathrm{p}, \mathrm{C}}}{\gamma_{\mathrm{M} 3}}
$$

ns - number of bolts in rows,

$\mu$ - slip factor,

ks - reduced factor for long slotted holes (ks=0.63),

$\mathrm{Y}_{\mathrm{M} 3}$ - partial safety factor taken as $\mathrm{YM} 3=1.25$.

2. Bearing resistance does not develop because the holes are slotted.

3. Elastic resistance (instead ultimate resistance) of the net cross section of shell:

$$
\mathrm{Z}_{\text {net,el, Rd }}=\left(\mathrm{c}-\mathrm{d}_{0}\right) \cdot \mathrm{s} \cdot \frac{\mathrm{f}_{\mathrm{y} \text {, shell }}}{\gamma_{\mathrm{M} 0}}
$$

c - segment width (distance between two bolt rows),

$\mathrm{d}_{0}$ - diametar of the hole,

$\mathrm{s}$ - shell tickness,

fy,shell - characteristic yield strength of shell material,

$\mathrm{V}_{\mathrm{MO}}-$ partial safety factor taken as $\mathrm{YM} 0=1.00$

The friction surfaces and corresponding slip factor values predicted in EN 1090, Part 2 are described in the following table.

Table 2. Classification that may be assumed for friction surfaces

\begin{tabular}{|l||c||c||}
\hline \multicolumn{1}{|c||}{ Surface treatment } & Class & Slip factor $\boldsymbol{\mu}$ \\
\hline Surfaces blasted with shot or grit with loose rust removed, not pitted. & A & 0,50 \\
\hline $\begin{array}{l}\text { Surfaces blasted with shot or grit: } \\
\text { a) spray-metallized with a aluminium or zinc based product, } \\
\text { b) with alkali-zinc silicate paint with a thickness of } 50 \mu \mathrm{m} \text { to } 80 \mu \mathrm{m}\end{array}$ & B & 0,40 \\
\hline Surfaces cleaned by wire-brushing or flame cleaning, with loose rust remover & C & 0,30 \\
\hline Surfaces as rolled & D & 0,20 \\
\hline
\end{tabular}


In wind towers in general the surfaces are blasted and zinc coated ( $\mu=0,40$ to 0,50$)$.

For other surface treatment - the slip factor may be obtained through experimental tests, in accordance with the normalized procedure described in Annex G of EN 1090, Part 2.

\section{CONCLUSION}

Advantages (compared with actual flange connections) of the new configuration (friction connection) for use in wind towers are:

1. simpler to fabrication,

2. less expensive,

3. easy to assembly in situ - open slotted holes allowed the angular alignment while the upper segment is slide down to the final position,

4. slot weaken the lower section providing less sensitivity to the assembling tolerance (lower parts between slotted holes may bent),

5. the shell bending stiffness is stiffened by the overlapping connection and

6 . better fatigue resistance.

7. Following table illustrate material costs for friction connections (defined by type and number of bolts).

Table 3. Prices of friction connections

\begin{tabular}{|c|c|c|c|}
\hline Component & $\begin{array}{c}\text { Unite } \\
\text { price }[€]\end{array}$ & Amount & Total price [€] \\
\hline \hline \multicolumn{3}{|c|}{ Connection 1 } \\
\hline $\begin{array}{c}\text { Bolt (M30x110 } \\
\text { S10T) }\end{array}$ & 5,45 & 588 & 3205 \\
\hline \hline \multicolumn{4}{|c|}{ Connection 2 } \\
\hline \hline $\begin{array}{c}\text { Bolt (M30x110 } \\
\text { S10T) }\end{array}$ & 5,45 & 351 & 1913 \\
\hline \hline
\end{tabular}

Table 4. Prices of bolted flange ring connections

\begin{tabular}{|c|c|c|c|}
\hline Component & $\begin{array}{c}\text { Unite } \\
\text { price }[€]\end{array}$ & Amount & Total price [€] \\
\hline \multicolumn{4}{|c|}{ Connection 1 } \\
\hline $\begin{array}{c}\text { Flange } \\
\text { (da=3917mm) }\end{array}$ & 6762 & 2 & 13524 \\
\hline $\begin{array}{c}\text { Bolt (M42x245 } \\
\text { 10.9) }\end{array}$ & 20,32 & 124 & 2520 \\
\hline \hline \multicolumn{4}{|c|}{ Connection 1 } \\
\hline \hline $\begin{array}{c}\text { Flange } \\
\text { (da=3448mm) }\end{array}$ & 4395 & 2 & 16044 \\
\hline $\begin{array}{c}\text { Bolt (M36x205 } \\
10.9)\end{array}$ & 11,40 & 116 & 1322 \\
\hline
\end{tabular}

At this moment, bolted ring flange connection is most often used assembling detail for wind towers. Table 4 illustrate material costs for this type of connection (defined by the radius and type of bolts) and it is very obvious that friction connections are much less expensive.

\section{REFERENCE}

1) EN 1993-1-8 (2005). "Eurocode 3 - Design of steel structures - Part 1-8: Design of joints", CEN, Brussels, Belgium.

2) EN 1090-2 (2008). "Execution of steel structures and aluminium structures - Part 2: Technical requirements for steel structures."

3) EN 1993-1-9 (2005). "Eurocode 3 - Design of steel structures - Part 1-9: Fatigue", CEN, Brussels, Belgium.

4) Husson W. 2008. Friction connections with slotted holes for wind towers. Luleå University of Technology. 2008:45.

5) Heistermann C. 2011. Behaviour of Pretensioned Bolts in Friction Connections. Luleå University of Technology. 2011.

6) Training Course Wind towers: Design by FEM and Technological Features, Coimbra, Portugal, 2011.

7) N. Fric, M. Pavlović, Z. Marković, D. Buđevac: "WIND TOWERS - DESIGN OF FLANGE RING CONNECTION", 14th International Symposium MASE, Struga, Macedonia, 2011., p.259-264

Paper sent to revision: 09.03.2012.

Paper ready for publication: 02.04.2012. 